\title{
Effect of Population Density of Kerria lacca Kerr. on its Growth and Survival
}

\author{
Shivam Vajpayee, Rahul Patidar, Sumit Kakade, Moni Thomas*, \\ Niraj Tripathi, A.K. Bhowmick, A.S. Gontia, P.S. Kulhare and H.L. Sharma \\ Jawaharlal Nehru Krishi Vishwa Vidyalaya, Jabalpur-482004, India \\ *Corresponding author
}

\section{A B S T R A C T}

Keywords

Pigeon pea, Insects,

Economical,

Competition,

Production

Article Info

Accepted:

10 November 2019

Available Online:

10 December 2019
A field experiment on effect of population density of lac insect Kerria lacca Kerr. on its growth and survival was conducted on Cajanus cajan, with seven treatments replicated thrice, during the year 2018-19. Lac insect population of $40,50,60,80,100$, natural population per $2.5 \mathrm{~cm}^{2}$ as well as no insect were the seven treatments the highest survival of lac insect from brood lac inoculation to harvest was 81.53 percent in the population density of 40 insects per $2.5 \mathrm{~cm}^{2}$. Highest of male insects was 6.67 per $2.5 \mathrm{~cm}^{2}$ in the natural population settlement of 127.39 lac insects per $2.5 \mathrm{~cm}^{2}$, while least 1.39 was in 60 lac insects per $2.5 \mathrm{~cm}^{2}$. Male emergence was observed between $129^{\text {th }}$ and $143^{\text {rd }}$ day after brood lac inoculation.

\section{Introduction}

Growth and survival of an organism depends on the population density, food, and shelter or protection (Basiago, 1999) available in the ecosystem. Intra-specific as well as interspecific competition (Grosholz, 1992) for food and survival is well acknowledged. Both these factors have an effective role in the population density also (Hansen et al., 1999).

Lac insect Kerria lacca Kerr. is a minute scale insect belonging to the family Tachardiidae (Kerriidae), superfamily Coccoidea of the order Hemiptera (Pal 2009 and Mohanta et al., 2012). It is economically important insect specially due to lac it produce and lac is a minor forest produce (Shah et al., 2015), cash crop (Ramani et al., 2007) and an export commodity (Anon, 2005). Lac production and productivity depends on its host management, quality of brood use (Shah et al., 2015) and live lac insects settled (Khobragade et al., 2012, Rathore 2011, Jhangel et al., 2013, Namdev et al., 2015, Sharma et al., 2015, Ghugal et al., 2015 and Sahu et al., 2016) till the maturity of the lac crop. Quantity of brood to be use for effective inoculation of lac insect 
have been studied (Kumar et al., 2017) in the past, but effective population density at initial settlement for maximum live lac insect at maturity of lac crop is as an important information gap. Thus, the present field study was conducted to generate data to fill the existing knowledge gap on lac insects.

\section{Materials and Methods}

The present field trial was conducted in Jawaharlal Nehru Krishi Vishwa Vidyalaya, Jabalpur, Madhya Pradesh between June 2018 to May 2019.The topography of the experimental area was fairly uniform. The Randomized Block Design experiment had seven treatments and three replication of Cajanus cajan variety TJT-501. The plant to plant and row to row spacing was $6 \mathrm{ft} \times 6 \mathrm{ft}$. There were three plants per replication of each of the seven treatments.

\section{Climate}

The climate of Jabalpur district is typically Sub humid, featured by hot dry summer and cool dry winter. Jabalpur is situated between $23^{\circ} \quad 09^{\prime}$ North latitude and $79^{\circ} \quad 58^{\prime}$ East longitudes at an altitude of 411.78 meters above the mean sea level. Jabalpur district lies in the Agro- climatic zone VII i.e. Kymore Plateau and Satpura Hills and Agro-ecological region number 10 [Central Highlands (Malwa and Bundhelkhand)], Sub region number 10.1, [hot sub-humid eco-region (Malwa Plateau, Vindhyan scarp land and Narmada Valley)].

Weather conditions were almost favourable for the growth and development of pigeon pea. The monsoon commenced in the first week of July and terminated in the $1^{\text {st }}$ week of October. The total rainfall received during the crop season was $1162.90 \mathrm{~mm}$, which was equally distributed in 58 rainy days from July to last week of May. Minimum and maximum mean temperature ranged from $4.80{ }^{0} \mathrm{C}$ to $24.90{ }^{0} \mathrm{C}$ and 28.50 to $41.80{ }^{0} \mathrm{C}$, respectively. The relative humidity ranged between 82 to 87 percent in the morning and 29 to 55 percent in the evening. The sunshine hours varied between 0.50 to 10.30 hours per day. The details of the treatment are given in Table 1 .

\section{Nursery raising of $C$. cajan}

Nursery of $C$. cajan was raised in the month of May 2018 on the substrate $(\mathrm{Kapu}+\mathrm{FYM})$ filled polythene bag $(18 \times 16 \mathrm{~cm})$ by sowing seeds treated with Trichoderma viridae, Rhizobium and PSB. Polythene bags were perforated to drain out excess irrigation water applied at weekly intervals. Polythene bags were kept in shade.

The seedlings were sprayed with insecticides to prevent insect pest incidence. The growing tips of the seedlings were nipped at 8-12 days interval till its transplantation Nipping was done to train the seedlings to a bush form.

\section{Layout of the field}

The layout of the experiment was planned in the main field to accommodate 63 C. cajan plants. The spacing between plant to plant and row to row in the main field was six feet apart. The spacing between replications was maintained at a spacing of 10 feet.

\section{Substrate}

The seedlings of $C$. cajan was transplanted in used polypropylene bags(PPB) of size $93 \mathrm{~cm} \mathrm{x}$ $61 \mathrm{~cm}$ filled with substrate consisting of a mixture of $45 \mathrm{~kg}$ river bed basin soil (Kapu) and $20 \mathrm{~kg}$ well rotten Farmyard manure (FYM). The Kapu and FYM in the above ratio were thoroughly mixed with the help of a spade to obtain a homogenized substrate. The physio-chemical property of the substrate is mentioned in the. The substrate was gradually filled into the PPB with help of a tasala 
followed by constant shaking the bag to ensure proper settlement and compactness of the substrate. The $65 \mathrm{~kg}$ substrate filled PPB attains a dimension of $46 \mathrm{~cm}$ height and 125 $\mathrm{cm}$ circumference.

The PPB was filled with substrate on the designated spot in the layout of the experiment, such that it is not disturbed in future Table 2.

\section{Treatment of the substrate}

PPB filled with substrate that was placed in the designated spot as per the experimental design, and was treated with microbes as per the treatments. The microbes were thoroughly mixed in the substrate.

\section{Transplantation of $C$. cajan saplings}

C. cajan saplings on attaining a height varying from 1.5 feet to 2 feet were transported to the main field. Each of the 63 saplings were place at the base of substrate filled PP.

The polythene bag of the $C$. cajan saplings was carefully removed without disturbing the root system. The sapling with substrate base is carefully transplanted in the PPB and pressed tightly from all corners, followed by watering. The transplantation was done in the evening hours of $15^{\text {th }}$ August 2018.

\section{Irrigation}

Each of the PPB with $C$. cajan plant was irrigated at regular intervals. Between August to October 2018, it was at 30 days interval while from November 2018 to February 2019 the interval of irrigation was 15 days, but from March 2019 to May 2019, the irrigation schedule was at 10 days interval. Approximately 10 liters water was given per plant during each irrigation with the help of polyethene pipe fitted to the tap in the field.

\section{Nipping}

The transplanted $C$. cajan was again nipped at 8-10 days interval till the last week of September, 2018.

\section{Application of pesticides}

Three sprays of pesticides on $C$. cajan pants were carried out as mentioned in Table 3.

\section{Brood lac inoculation}

Rangeeni brood lac purchased from Adarsh Lac Samiti, Jamankhari village, Tehsil Barghat, district Seoni, M.P. on 02.11.2018 was sorted for quality and predator free brood, before its inoculation on $C$. cajan.

Brood lac stick weighing $15 \mathrm{~g}$ was tied at the base of each $C$. cajan in the PPB on 03.11.2018 with the help of a twine as per the treatments.

\section{Lac insect count}

Lac insects were counted per $2.5 \mathrm{~cm}^{2}(2.5 \mathrm{~cm}$ length and $1.0 \mathrm{~cm}$ width) space on the stem or branch as the case may be.

\section{Marking of slot}

Once lac insect inserts its stylet into the phloem, it becomes sedentary. Thirty days after BLI, branches with good lac insect settlement were selected for marking of slot of $2.5 \mathrm{~cm} \times 1 \mathrm{~cm}$ size on the bark.

Three slots were made on plant each of $2.5 \mathrm{~cm}^{2}$. Each slots were designated as $\mathrm{S}_{1}, \mathrm{~S}_{2}$, and $S_{3}$. Later stretching a thread between the index fingers of both the hands the lac insect settlements adjacent to the boundaries of the slot is carefully removed to make the slot differentiate from the rest of the lac settlement on the branch. 


\section{Digital recording of the insects}

Lac insect settlement within the slot was digitally photographed with the help of a Digital Single Lens Reflex (DSLR) camera fitted with $100 \mathrm{~mm}$ micro lens by settling it in manual mode with ISO 400 and shutter speed of 4.5 to 6 . Several pictures of the slot was taken for clarity, finally the best click was selected and counted with the help of paint 3D program.

\section{Frequency of lac insect count}

Counting of lac insects within the slots was done at $65^{\text {th }}, 70^{\text {th }}, 95^{\text {th }}, 125^{\text {th }}, 155^{\text {th }}$ and $185^{\text {th }}$ day after BLI. On $70^{\text {th }}$ day of BLI, the number of lac insects were adjusted as per treatments i.e., $\mathrm{T}_{1}, \mathrm{~T}_{2}, \mathrm{~T}_{3}, \mathrm{~T}_{4}, \mathrm{~T}_{5}, \mathrm{~T}_{6}$ and $\mathrm{T}_{7}$ with 80,100 , 40, 50, 60, no lac insect (control) and natural settlement respectively.

\section{Emergence of male lac insects}

The date of emergence of male lac insects as well as its duration was recorded.

\section{Data analysis}

Data was analyzed using parameters given in the Table 4.

The significance among different treatment means was judged by critical difference (C.D) at 5\% level of significance for comparison among the treatments, for which the marginal means of each treatment was considered. The following formula was used for various estimations.

Standard error of mean SEm $\pm=\sqrt{\frac{E_{m s}}{r}}$

Critical difference (C.D.) $=\operatorname{SEm} \pm \mathrm{x} \sqrt{2} \mathrm{xt}$ 0.05

where,
Ems $=$ error mean sum of square

$t=$ ' $\mathrm{t}$ ' value at $5 \%$ level at error d.f.

$\mathrm{r}=$ number of replications

$\mathrm{SEm} \pm=$ standard error of any treatment mean

$\mathrm{CD}=$ Critical difference

\section{Results and Discussion}

\section{Live lac insects per $2.5 \mathrm{~cm}^{2}$ on $65^{\text {th }}$ day after BLI (07.01.2019)}

The mean number of live lac insects settled per $2.5 \mathrm{~cm}^{2}$ of the branches varied from 60.33 to 140.17 (Table 5) on $65^{\text {th }}$ day after BLI (07.01.2019). C. cajan plants in all the treatments were inoculated with brood lac except treatment $\mathrm{T}_{6}$ which was kept free of lac insects. Counting of the settlement of lac insects in a unit space of $2.5 \mathrm{~cm}^{2}(2.5 \mathrm{~cm}$ long and $1.00 \mathrm{~cm}$ width) space on the lac insect settled branches is considered as a standard protocol by earlier workers viz., Khobragade, (2010), Rathore, (2011), Patel, (2013), Bhalerao, (2013), Shah et al.,(2014), Sharma et al., (2015), Gurjar, (2016), Ghugal et al., (2016), Namdev et al., (2015), Kumar et al., (2017) and Shah et al., (2018).

However Mohanta et al., (2014), Kalahal et al., (2017), Sharma et al., (2018) and Hazarika et al., (2018) has reported lac insect count from $1 \mathrm{~cm}^{2}$. Counting of larvae insects of size varying from 0.2 to $0.5 \mathrm{~mm}$ with in a small space of $1 \mathrm{~cm}$ is extremely difficult in field condition, while from $2.5 \mathrm{~cm}^{2}$ is quite comfortable.

Adjustment population density of live lac insects on $70^{\text {th }}$ day after BLI (12.01.2019)

The density of live lac insects (no. per $2.5 \mathrm{~cm}^{2}$ ) was adjusted according to the treatments by 
removing excess live lac insects. Finally, all the slots on the $C$. cajan of treatments $\mathrm{T}_{1}, \mathrm{~T}_{2}$, $\mathrm{T}_{3}, \mathrm{~T}_{4}, \mathrm{~T}_{5}$ and $\mathrm{T}_{7}$ had 80, 100, 40, 50, 60 and 127.39 lac insects per $2.5 \mathrm{~cm}^{2}$.

The treatment $\mathrm{T}_{7}$ had mean natural population density 127.39 per $2.5 \mathrm{~cm}^{2}$ i.e., the naturally settled live lac insects that was left undisturbed and $\mathrm{T}_{6}$ had no lac insect (Table 5). There was a reduction in the mean live lac insect count per $2.5 \mathrm{~cm}^{2}$ on the branches after $70^{\text {th }}$ day of BLI in all the treatments during the growth stages of the lac insects.

Initial settlement of lac insects per $2.5 \mathrm{~cm}^{2}$ space is reported to vary from 52.40 to 63.0 (Khobragade, 2010), 130.44 to 179.54 (Rathore, 2011), 61.40 to 102.60 (Patel, 2013), 37.95 to 58.24 (Sharma et al., 2015), 79.32 to 90.02 (Namdev, 2014), 42.88 to 46.44 (Gurjar, 2016), 49.95 to 51.11 (Ghugal et al., 2016), 44.95 to 50.28 (Kumar et al., 2017) and 84.01 to 88.54 (Shah et al., 2018). Thus, in view of the past studies in the present study the population densities per $2.5 \mathrm{~cm}^{2}$ were fixed to $0,40,50,60,80,100$ and natural settlement (127.39).

Live lac insects in different population densities on $95^{\text {th }}$ day after BLI (07.02.2019)

The mean number of live lac insects settlement per $2.5 \mathrm{~cm}^{2}$ was maximum (98.06) in the population density 127.39 per $2.5 \mathrm{~cm}^{2}$ while it was minimum (39.28) in population density of 40 insects per $2.5 \mathrm{~cm}^{2}$ at $95^{\text {th }}$ day after BLI. There was significant difference in the mean number of live lac insects per $2.5 \mathrm{~cm}^{2}$ in 80,100 , and 127.39 per $2.5 \mathrm{~cm}^{2}$ over 40,50 , 60 and 0 insects per $2.5 \mathrm{~cm}^{2}$. The mean live lac insects in the latter four population densities were at par with each other. Among the former three, 80 and 100 were at par with each other but significantly differed with the population density 127.39 per $2.5 \mathrm{~cm}^{2}$ in terms of mean live lac insect count.
Live lac insects in different population densities on $125^{\text {th }}$ day after BLI (07.03.2019)

The mean number of lac insects per $2.5 \mathrm{~cm}^{2}$ continued to reduce in comparison to that on $95^{\text {th }}$ day after BLI. It was maximum 79.11 in the population density of 127.39 per $2.5 \mathrm{~cm}^{2}$ while it was minimum $33.78 \mathrm{~cm}$ in that with population density of 60 insects per $2.5 \mathrm{~cm}^{2}$ on $125^{\text {th }}$ day after BLI.

The mean of live lac insects per $2.5 \mathrm{~cm}^{2}$ in the population density of 80,100 and 127.39 per $2.5 \mathrm{~cm}^{2}$ were significantly more over rest of the treatments.

However, the mean number of live lac insects in the population densities of 80 and 100 insects per $2.5 \mathrm{~cm}^{2}$ were at par with each other, while that in population density of 127.39 per $2.5 \mathrm{~cm}^{2}$ differed significantly.

Live lac insects in different population densities on $155^{\text {th }}$ day after BLI (07.04.2019)

The mean number of live lac insects per $2.5 \mathrm{~cm}^{2}$ on $155^{\text {th }}$ day after BLI continued to reduce from $70^{\text {th }}$ day after BLI.

The mean number of mean live lac insects per $2.5 \mathrm{~cm}^{2}$ was maximum 72.44 in $C$. cajan with population density of 127.39 per $2.5 \mathrm{~cm}^{2}$ while it was minimum 32.39 in $C$. cajan with population density of 60 insects per $2.5 \mathrm{~cm}^{2}$ on $155^{\text {th }}$ day after BLI.

The mean number of live lac insects per $2.5 \mathrm{~cm}^{2}$ in the population density of 80,100 and 127.39 per $2.5 \mathrm{~cm}^{2}$ were significantly more over rest of the treatments with BLI.

However the mean number of live lac insects in population densities of 80,100 and 127.39 per $2.5 \mathrm{~cm}^{2}$ were at par with each other. 
Live lac insects in different population densities on $185^{\text {th }}$ day after BLI (07.05.2019)

The mean number of live lac insects per $2.5 \mathrm{~cm}^{2}$ on $185^{\text {th }}$ day after BLI varied from a minimum of 31.28 in the population density of 60 insects per $2.5 \mathrm{~cm}^{2}$ to 70.89 in the population density of 127.39 per $2.5 \mathrm{~cm}^{2}$. The mean numbers of live lac insects in the population densities of 80,100 and 127.39 per $2.5 \mathrm{~cm}^{2}$ were significantly more over 40,50 and 60 insects per $2.5 \mathrm{~cm}^{2}$ with BLI. The mean number of live lac insects in the population densities of 80,100 and 127.39 per $2.5 \mathrm{~cm}^{2}$ were at par with each other. Similarly it was at par with each other in population density 40,50 and 60 insects per $2.5 \mathrm{~cm}^{2}$. The mean live lac insects in different treatment is reported to vary from 60 to 95.80 (Patel, 2013), 28.13 to 40.53 (Jhanghel, 2013), 51.35 to 64.08 (Namdev, 2014), 38.31 to 43.37 (Gurjar, 2016), 37.05 to 39.34 (Kumar et al., 2017) and 57.48 to 64.08 (Shah et al., 2018). During different growth period the number of live lac insects varied in the previous studies as there was a variation in the host, season, lac insect strain, location and treatments of their study. However, these studies indicate the trend of the live lac insects on $2.5 \mathrm{~cm}^{2}$ during its growth phases in comparison to that occurred at BLI.

\section{Survivability of Lac insects at different} population densities

We have to understand that among many of the deciding factors for the Lac crop productivity, the percent survival of Lac insects from the BLI to harvest is one of the important factors, as lac is produced by Lac insect. Now, there are again two sub factors in the population density that can play a vital role in Lac production. The emergence and presence of male lac insects, in the lac ecosystem is one sub factor while another sub factor is the loss in the number of Lac insects before and after emergence of the male lac insects. This will matter though be discussed later but the data must be looked with that perspective.

The percent survival of Lac insects is reported in three phases of Lac insect growth after BLI. The duration between $70^{\text {th }}$ to $125^{\text {th }}$ day are usually larval growth and pupal period of the Rangeeni lac insects during summer crop (October to May-June). Male emergence and mating takes place between $125^{\text {th }}$ to $155^{\text {th }}$ day, while the major lac secretion phase is after mating of lac insect i.e., $150^{\text {th }}$ day onwards in case of Baishakhi crop of Rangeeni lac.

Between $70^{\text {th }}$ to $95^{\text {th }}$ day after BLI, the maximum survival of Lac insects was 98.20 percent in the population density of 40 insects per $2.5 \mathrm{~cm}^{2}$ closely followed by that 94.45 percent in the case of 80 insects per $2.5 \mathrm{~cm}^{2}$. The lowest percent $(73.70 \%)$ survival of Lac insect during this period was in the population density of 60 insects per $2.5 \mathrm{~cm}^{2}$. In comparison to the live lac insects during $70^{\text {th }}$ to $95^{\text {th }}$ day after BLI the maximum survival of lac insects during the $95^{\text {th }}$ to $125^{\text {th }}$ day period was 92.45 and 92.21 percent in the population densities of 50 and 40 insects per $2.5 \mathrm{~cm}^{2}$ respectively. The minimum percent $(76.39 \%)$ survival of Lac insects during this period continued in the population density of 60 insects per $2.5 \mathrm{~cm}^{2}$. However during the $125^{\text {th }}$ to $155^{\text {th }}$ day period the percent survival of lac insects over that during $95^{\text {th }}$ to $125^{\text {th }}$ day period was very high in all the population densities as it varied from 91.57 to 96.50 percent. Similar, in survival percent of Lac insects during $155-185$ days period over $125^{\text {th }}$ to $155^{\text {th }}$ day was still higher ranging from 94.84 to 97.86 percent.

The above was the survival percent of the Lac insects during its various growth phases focusing a comparison among the population 
densities and with the mean number of live lac insect count of preceding growth phase. The survival percent of lac insects among the population densities when compared from $70^{\text {th }}$ days to $185^{\text {th }}$ day after BLI, it was maximum $(81.53 \%)$ in the population density of 40 insects per $2.5 \mathrm{~cm}^{2}$. The survival was 65.70 , 65.55 and 62.50 percent in the population densities of 80,50 and 100 insects per $2.5 \mathrm{~cm}^{2}$ which were very close to each other. The lowest survival of 52.13 and 55.65 percent was observed in 60 and 127.39 insects per $2.5 \mathrm{~cm}^{2}$.

Survivability of lac insects from BLI to maturity of crop has been reported by many workers. Shah et al., (2014) reported it from 10.71 to 17.21 percent, while according to Gurjar, (2016) it was from 34.08 to 51.53 percent. Sharma et al., (2015) reported it to be from 33.53 to 41.77 percent in different treatments, while according to Kumar et al., (2017) it varied from 20.86 to 26.05 percent. Namdev et al., (2015) and Shah et al., (2018) also reported that it to varied from 19.63 to 20.58 percent and 20.47 to 23.52 percent respectively in case of Kusmi lac on Z. mauritiana.

\section{Loss of Lac insects from $70^{\text {th }}$ to $185^{\text {th }}$ day after BLI}

There occurred a loss in the mean number of Lac insects per $2.5 \mathrm{~cm}^{2}$ in all the population densities during the growth stages of the Lac insects. Loss of insects means death of insect due to various reasons. In order to simplify the complex information, the loss of Lac insects is reported in percent (Table 6).

During $70^{\text {th }}$ to $95^{\text {th }}$ day after BLI, the percent loss of Lac insect was lowest $(1.8 \%)$ in the population density of 40 insects per $2.5 \mathrm{~cm}^{2}$. It was followed by 5.55, 18.0, 20.56, 23.63 and 26.30 percent respectively in population densities of 80,100, 50, 60 and 127.39 insects per $2.5 \mathrm{~cm}^{2}$. This trend was not observed during $95^{\text {th }}$ to $125^{\text {th }}$ day period, where the minimum insect loss was of 7.56 percent in the population density of 50 insects per $2.5 \mathrm{~cm}^{2}$. It was closely followed by 7.78 percent in the population density of 40 insects per $2.5 \mathrm{~cm}^{2}$. The maximum loss of Lac insects $(23.62 \%)$ during this period was observed in the population density of 60 insects per $2.5 \mathrm{~cm}^{2}$. The percent loss of Lac insects was more during $95^{\text {th }}$ to $125^{\text {th }}$ day period over $70^{\text {th }}$ to $95^{\text {th }}$ day. But there was a reduction in the percent loss of Lac insects in almost all the population densities during $125^{\text {th }}$ to $155^{\text {th }}$ day period in comparison to that during $95^{\text {th }}$ to $125^{\text {th }}$ day. The minimum loss of Lac insects was 3.50 and 4.11 percent population densities of 100 and 60 insects per $2.5 \mathrm{~cm}^{2}$, while the maximum loss of 8.43 and 8.23 percent was in 127.39 and 80 insects per $2.5 \mathrm{~cm}^{2}$ respectively.

The percent loss of Lac insects during $155^{\text {th }}$ to $185^{\text {th }}$ day period was just 2.14 and 2.77 percent in population densities of 127.39 and 100 insects per $2.5 \mathrm{~cm}^{2}$ while maximum loss of 5.16 percent was in the population density of 50 insects per $2.5 \mathrm{~cm}^{2}$.

Loss of lac insect during its growth stages is common and reported by previous worker viz., Khobragade, (2010), Patel, (2013), Jhanghel, (2013), Bhalerao, (2013), Namdev, (2014), Ghugal, (2015), Gurjar, (2016), Sahu, (2016) and Shah et al., (2018). The percent loss of lac insect from BLI to maturity or harvest varies and depends on the various conditions. The mean percent lac insect loss ranged from 7.62 to 16.83 percent (Khobragade, 2010), while according to Patel, (2013) it ranged from 69.14 to 74.52 percent. Bhalerao, (2013) reported it from 73.95 to 81.63 percent, while Jhanghel, (2013), Namdev, (2014), Ghugal et al., (2016) and Kumar et al., (2017) reported it to vary from 68.10 to $73.01,79.42$ to 80.37 , 39.60 to 63.41 and 22.99 to 28.85 percent respectively. 
Table.1 The details of the treatments and notations used are as below

\begin{tabular}{|c|}
\hline Treatments (Population density per $\left.2.5 \mathrm{~cm}^{2}\right)$ \\
\hline$T_{1}=80$ lac insects \\
\hline $\mathbf{T}_{2}=\mathbf{1 0 0}$ lac insects \\
\hline $\mathbf{T}_{3}=40$ lac insects \\
\hline $\mathbf{T}_{4}=\mathbf{5 0}$ lac insects \\
\hline $\mathbf{T}_{5}=\mathbf{6 0}$ lac insects \\
\hline $\mathbf{T}_{6}=$ 0 lac insect \\
\hline $\mathbf{T}_{7}=$ Natural population density 127.39 \\
\hline
\end{tabular}

Table.2 Physico-chemical properties of the substrate $(65 \mathrm{~kg})$ filled in Poly propylene bag (PPB)

\begin{tabular}{|c|c|c|}
\hline Constituents & $\begin{array}{c}\text { Value } \\
(\mathbf{g} / \mathbf{6 5 k g} \text { substrate) }\end{array}$ & Method used \\
\hline Available $\mathrm{N}$ & 136.15 & Alkaline permanganate method (Subbiah and Asija, 1956) \\
\hline Available $\mathrm{P}_{2} \mathrm{O}_{5}$ & 45 & Calorimeter method (Olsen et al., 1954) \\
\hline Available $\mathrm{K}_{2} \mathrm{O}$ & 304 & Flame Photometer method (Chapman and Pratt, 1961) \\
\hline
\end{tabular}

Table.3 Spray schedule of pesticides

\begin{tabular}{|c|c|c|c|c|}
\hline Spray & Chemical & Dose & Day & Remark \\
\hline First & Emamectin benzoate & $1 \mathrm{~g} /$ liter & $30 \mathrm{DAT}$ & To manage foliage feeders \\
\hline Second & Cartap hydrochloride & $1 \mathrm{~g} / \mathrm{liter}$ & $\begin{array}{c}30 \text { days } \\
\text { after BLI }\end{array}$ & $\begin{array}{c}\text { To manage predators and } \\
\text { parasites of lac insect }\end{array}$ \\
\hline Third & Cartap +Diethane M-45 & $2 \mathrm{~g} / \mathrm{liter}$ & $\begin{array}{c}60 \text { days } \\
\text { after BLI }\end{array}$ & $\begin{array}{c}\text { To manage predator and } \\
\text { parasites of lac insect and } \\
\text { sooty mold }\end{array}$ \\
\hline
\end{tabular}

$*$ DAT $=$ Days after transplanting, $*$ BLI $=$ Brood lac inoculation

Table.4 Skeleton of Analysis of Variance (ANOVA)

\begin{tabular}{|c|c|c|c|c|c|}
\hline Source of variance & d.f. & S.S & M.S.S & F.cal & F. tab \\
\hline Replication & $(\mathrm{r}-1)$ & SSR & VR & VR/VE & - \\
\hline Treatments & $(\mathrm{t}-1)$ & SST & VT & VT/VE & $\begin{array}{c}\text { F at 5\% (t-1), } \\
(\mathrm{r}-1)(\mathrm{t}-1)\end{array}$ \\
\hline Error & $(\mathrm{r}-1)(\mathrm{t}-1)$ & SSE & VE & - & - \\
\hline Total & $(\mathrm{rt}-1)$ & - & - & - & - \\
\hline
\end{tabular}

where,

$\mathrm{r}=$ number of replications

$\mathrm{t}=$ number of treatments

$\mathrm{V}=$ replication mean sum of square

$\mathrm{VT}=$ treatment mean sum of square

$\mathrm{VE}=$ error mean sum of square 
Table.5 Mean number of live lac insects settled per $2.5 \mathrm{~cm}^{2}$ on the $C$. cajan branches under different treatments

\begin{tabular}{|c|c|c|c|c|c|c|c|}
\hline \multirow{2}{*}{$\begin{array}{l}\text { Treatments } \\
\left(\text { Pop }^{n} \text { density }\right. \\
\left.\text { per } 2.5 \mathrm{~cm}^{2}\right)\end{array}$} & \multicolumn{7}{|c|}{ Mean number of live lac insects settlement per $2.5 \mathrm{~cm}^{2}$ at days after BLI } \\
\hline & $65^{\text {th }}$ & $70^{\text {th }}$ & $95^{\text {th }}$ & $125^{\text {th }}$ & $155^{\text {th }}$ & $185^{\text {th }}$ & $\begin{array}{c}\text { Mean survival } \\
(\%)\end{array}$ \\
\hline $\begin{array}{c}T_{1}=80 \text { lac } \\
\text { insects }\end{array}$ & $\begin{array}{l}130.83 \\
(11.46)\end{array}$ & $\begin{array}{l}80.00 \\
(8.97)\end{array}$ & $\begin{array}{l}75.56 \\
(8.72)\end{array}$ & $\begin{array}{l}59.39 \\
(7.73)\end{array}$ & $\begin{array}{l}54.50 \\
(7.39)\end{array}$ & $\begin{array}{l}52.56 \\
(7.26)\end{array}$ & 65.70 \\
\hline $\begin{array}{c}T_{2}=100 \text { lac } \\
\text { insects }\end{array}$ & $\begin{array}{l}140.17 \\
(11.3)\end{array}$ & $\begin{array}{l}100.00 \\
(10.02)\end{array}$ & $\begin{array}{l}82.00 \\
(9.06)\end{array}$ & $\begin{array}{l}66.61 \\
(8.18)\end{array}$ & $\begin{array}{l}64.28 \\
(8.03)\end{array}$ & $\begin{array}{l}62.50 \\
(7.92)\end{array}$ & 62.50 \\
\hline $\begin{array}{c}T_{3}=40 \text { lac } \\
\text { insects }\end{array}$ & $\begin{array}{l}79.06 \\
(8.92)\end{array}$ & $\begin{array}{l}40.00 \\
(6.36)\end{array}$ & $\begin{array}{l}39.28 \\
(6.31)\end{array}$ & $\begin{array}{l}36.22 \\
(6.06)\end{array}$ & $\begin{array}{l}34.28 \\
(5.90)\end{array}$ & $\begin{array}{l}32.61 \\
(5.75)\end{array}$ & 81.53 \\
\hline $\begin{array}{c}T_{4}=50 \text { lac } \\
\text { insects }\end{array}$ & $\begin{array}{l}60.33 \\
(7.46)\end{array}$ & $\begin{array}{l}50.00 \\
(7.11)\end{array}$ & $\begin{array}{l}39.72 \\
(6.34)\end{array}$ & $\begin{array}{l}36.72 \\
(6.10)\end{array}$ & $\begin{array}{l}34.50 \\
(5.92)\end{array}$ & $\begin{array}{l}32.72 \\
(5.76)\end{array}$ & 65.44 \\
\hline $\begin{array}{c}T_{5}=60 \text { lac } \\
\text { insects }\end{array}$ & $\begin{array}{l}137.11 \\
(11.69)\end{array}$ & $\begin{array}{l}60.00 \\
(7.78)\end{array}$ & $\begin{array}{l}44.22 \\
(6.66)\end{array}$ & $\begin{array}{l}33.78 \\
(5.85)\end{array}$ & $\begin{array}{l}32.39 \\
(5.73)\end{array}$ & $\begin{array}{l}31.28 \\
(5.64)\end{array}$ & 52.13 \\
\hline $\begin{array}{c}T_{6}=0 \text { lac } \\
\text { insect }\end{array}$ & $\begin{array}{c}0.00 \\
(0.71)\end{array}$ & $\begin{array}{c}0.00 \\
(0.71)\end{array}$ & $\begin{array}{c}0.00 \\
(0.71)\end{array}$ & $\begin{array}{c}0.00 \\
(0.71)\end{array}$ & $\begin{array}{c}0.00 \\
(0.71)\end{array}$ & $\begin{array}{c}0.00 \\
(0.71)\end{array}$ & 0.00 \\
\hline $\mathbf{T}_{7}=127.39 *$ & $\begin{array}{l}127.39 \\
(11.26)\end{array}$ & $\begin{array}{l}127.39 \\
(11.26)\end{array}$ & $\begin{array}{l}98.06 \\
(9.91)\end{array}$ & $\begin{array}{l}79.11 \\
(8.92)\end{array}$ & $\begin{array}{l}72.44 \\
(8.54)\end{array}$ & $\begin{array}{r}70.89 \\
(8.45)\end{array}$ & 55.65 \\
\hline $\mathbf{S E}(\mathbf{m}) \pm$ & 0.64 & 0.26 & 0.25 & 0.16 & 0.18 & 0.18 & \\
\hline CD at $5 \%$ & 1.98 & 0.82 & 0.76 & 0.51 & 0.57 & 0.58 & \\
\hline
\end{tabular}

*Figure in parenthesis are transformed values $\sqrt{x+0.05}$

*mean natural population density

Table.6 Percent of loss in the mean number of lac insects per $2.5 \mathrm{~cm}^{2}$

\begin{tabular}{|c|c|c|c|c|}
\hline \multirow{2}{*}{$\begin{array}{c}\text { Treatments } \\
\left(\text { Pop }^{\mathrm{n}} \text { density per }\right. \\
\left.2.5 \mathrm{~cm}^{2}\right)\end{array}$} & \multicolumn{4}{|c|}{$\begin{array}{l}\text { Percent of loss in the mean no. of lac insects per } 2.5 \mathrm{~cm}^{2} \text { at different } \\
\text { periods after BLI }\end{array}$} \\
\hline & $\begin{array}{l}70^{\text {th }} \text { to } 95^{\text {th }} \\
\text { day }\end{array}$ & $95^{\text {th }}$ to $125^{\text {th }}$ day & $125^{\text {th }}$ to $155^{\text {th }}$ day & $\begin{array}{l}155^{\text {th }} \text { to } 185^{\text {th }} \\
\text { day }\end{array}$ \\
\hline$T_{1}=80$ lac insects & 5.55 & 21.40 & 8.23 & 3.56 \\
\hline$T_{2}=100$ lac insects & 18 & 18.77 & 3.50 & 2.77 \\
\hline$T_{3}=40$ lac insects & 1.8 & 7.78 & 5.37 & 4.87 \\
\hline $\mathbf{T}_{4}=50$ lac insects & 20.56 & 7.56 & 6.05 & 5.16 \\
\hline$T_{5}=60$ lac insects & 26.3 & 23.62 & 4.11 & 3.43 \\
\hline $\mathbf{T}_{6}=0$ lac insect & 0.00 & 0.00 & 0.00 & 0.00 \\
\hline $\mathbf{T}_{7}=127.39 *$ & 23.03 & 19.32 & 8.43 & 2.14 \\
\hline
\end{tabular}

* mean natural population density 
Table.7 Sex ratio of lac insects on $155^{\text {th }}$ day after BLI

\begin{tabular}{|c|c|c|}
\hline $\begin{array}{c}\text { Treatments } \\
\left(\mathbf{P o p}^{\mathbf{n}} \text { density per } \mathbf{2 . 5} \mathbf{~ c m}^{\mathbf{2}}\right)\end{array}$ & $\begin{array}{c}\text { Number of Male lac } \\
\text { insects }\end{array}$ & Female \& Male ratio \\
\hline $\mathbf{T}_{\mathbf{1}}=\mathbf{8 0}$ lac insects & 4.89 & $11.15: 1$ \\
\hline $\mathbf{T}_{\mathbf{2}}=\mathbf{1 0 0}$ lac insects & 2.35 & $27.55: 1$ \\
\hline $\mathbf{T}_{\mathbf{3}}=\mathbf{4 0}$ lac insects & 1.94 & $17.63: 1$ \\
\hline $\mathbf{T}_{\mathbf{4}}=\mathbf{5 0}$ lac insects & 2.22 & $15.53: 1$ \\
\hline $\mathbf{T}_{\mathbf{5}}=\mathbf{6 0}$ lac insects & 1.39 & $23.32: 1$ \\
\hline $\mathbf{T}_{\mathbf{6}}=\mathbf{0}$ lac insect & 0.00 & $0: 00$ \\
\hline $\mathbf{T}_{\mathbf{7}}=\mathbf{1 2 7 . 3 9} *$ & 6.67 & $10.87: 1$ \\
\hline
\end{tabular}

* mean natural population density

In the present study, maximum loss of insect was during the immature stage of lac insects i.e., within $125^{\text {th }}$ day after BLI. High mortality of during immature stages of insects is reported by Khobragade (2010), Patel (2013), Jhanghel (2013), Bhalerao (2013), Namdev (2014), Ghugal et al., (2016), Gurjar (2016), Sahu (2016) and Shah et al., (2018). Thus higher percent loss within $125^{\text {th }}$ day of BLI is a natural phenomenon.

\section{Male emergence}

Adult male emergence was first observed on 12.03.2019, i.e., on $129^{\text {th }}$ day after the BLI. It was observed till 26.03.2019 i.e., on $143^{\text {th }}$ day after BLI. The duration of presence of adult males in the lac ecosystem was 14 days. This duration provides sufficient opportunity for the agile male to mate with numerous sedentary female lac insects. Both winged as well as wingless adult males were observed. Adult male lac insects within its short life period of three to four days should mate with as many as adult female lac insects. Thus, this growth phase of Lac insect is very important biologically (for generation) and economically (as female produces Lac). In this context more female lac is very important for increasing lac production. Male emergence (Rangeeni lac) at $110^{\text {th }}$ day after BLI in summer lac crop on $Z$. mauritiana is reported by Bhalerao, (2013), Patel, (2013) also reported male emergence (rangeeni lac) at $50^{\text {th }}$ day after BLI in katki crop on Z. mauritiana. Namdev, (2014) reported male emergence in Aghani crop of kusmi lac on Z. mauritiana between $65^{\text {th }}$ and $75^{\text {th }}$ day after BLI, when winged male lac insect were seen, which were short lived.

\section{Female to male ratio in lac insects}

As mentioned earlier, the adult male lac insects were observed in between $129^{\text {th }}$ and $143^{\text {th }}$ day after BLI. In the present study, the growth, survival and lac production of Lac insects was studied after the initial maintenance of different population densities of 40, 50,60,80,100 and 127.39 (natural settlement) per $2.5 \mathrm{~cm}^{2}$ on the branches on $70^{\text {th }}$ day after BLI. Counting of minute agile adult males from the population within the fixed slot size of $2.5 \mathrm{~cm}^{2}$ on the branches was very difficult, as any number of male insects from outside the slot can either enter or those in the slot can leave during the tedious counting process. In order to overcome this technical issue, the number of lac insects lost during the live insect count $\left(125^{\text {th }}\right.$ to $155^{\text {th }}$ day period) on $155^{\text {th }}$ day is taken into consideration as male insects because (a) they (males) were observed in between $129^{\text {th }}$ and $143^{\text {th }}$ day after BLI and (b) the life of adult male is just 3 to 4 days. That means even if the last male that may have emerged on $143^{\text {rd }}$ day is expected to live only till $147^{\text {th }}$ day, while 
the live insect count was done on the $155^{\text {th }}$ day. Another supporting data to this concept can be drawn from the, fact that the maximum percent of loss of Lac insects was during the period of $95^{\text {th }}$ and $125^{\text {th }}$ day. This period coincides with late larval and pupal stage of Lac insects, just 4 days after i.e., on $129^{\text {th }}$ day after BLI adult males emerged.

Taking all the above facts into consideration, the mean number of lac insects lost between $125^{\text {th }}$ and $155^{\text {th }}$ day after BLI is estimated as mean number of 'male insects' in different population densities under the present study. Thus, the mean number of live lac insect count per $2.5 \mathrm{~cm}^{2}$ on the $155^{\text {th }}$ day was the live female lac insects. Accordingly the mean number of adult male lac insects in the population densities of 40, 50, 60, 80, 100 and 127.39 insects per $2.5 \mathrm{~cm}^{2}$ was $1.94,2.22$, $1.39,4.89,2.35$ and 6.67 respectively. Thus a reliable data of male and female lac insects is generated for calculating the female to male sex ratio in the field condition. On this basis, the female to male was highest 27.55:1 in the population density of 100 insects per $2.5 \mathrm{~cm}^{2}$ closely followed by that $23.32: 1$ in the population density of 60 insects per $2.5 \mathrm{~cm}^{2}$. The female to male was lowest 10.87:1 in the population density of 127.39 insects per $2.5 \mathrm{~cm}^{2}$ closely followed by that $11.15: 1$ in the population density of 80 insects (Table 7) per $2.5 \mathrm{~cm}^{2}$.

Higher female lac insects in the lac production are a good signal for higher lac production, as female lac secretes lac (Rathore, 2011). Female to male sex ratio of lac insect is reported by many workers, but the variation in sex ratio of lac insects may be due to poor brood, improper brood lac inoculation, host tree management etc. Sex ratio reported by Rathore (2011) varied from 9.04:1 to 10.32: 1, while it was 2.46: 1 to 3.26: 1 reported by Bhalerao (2013).
The percent survival of lac insects is reported of four phases of lac insects growth i.e., between $70^{\text {th }}-95^{\text {th }}, 95^{\text {th }}-125^{\text {th }}, 125^{\text {th }}-155^{\text {th }}$ and $155^{\text {th }}-185^{\text {th }}$ day after BLI. The percent survival of lac insects was maximum (81.53) with population density of 40 insects per $2.5 \mathrm{~cm}^{2}$ and minimum (52.13) with population density of 60 insects per $2.5 \mathrm{~cm}^{2}$.

The loss period of lac insects is reported of four phases i.e., between $70^{\text {th }}-95^{\text {th }}, 95^{\text {th }}-125^{\text {th }}$, $125^{\text {th }}-155^{\text {th }}$ and $155^{\text {th }}-185^{\text {th }}$ day after BLI. The maximum percent of loss of Lac insects was during the period of $95^{\text {th }}-125^{\text {th }}$ day is 23.62 in population density of 60 insects per $2.5 \mathrm{~cm}^{2}$ and minimum percent loss is 2.14 in population density of 127.39 insects per $2.5 \mathrm{~cm}^{2}$ on $155^{\text {th }}-185^{\text {th }}$ day. During $75^{\text {th }}-95^{\text {th }}$ day minimum loss percent of lac insects 1.8 with population density of 40 insects per $2.5 \mathrm{~cm}^{2}$ and maximum 26.30 in population density of 127.39 insects per $2.5 \mathrm{~cm}^{2}$. Similarly in $95^{\text {th }}-125^{\text {th }}$ day minimum loss percent of lac insects 7.56 with population density of 50 insects per $2.5 \mathrm{~cm}^{2}$ and maximum 23.62 in population density of 60 insects per $2.5 \mathrm{~cm}^{2}$. The percent loss of lac insects during $125^{\text {th }}$ $155^{\text {th }}$ day was minimum 3.50 with population density of 100 insects per $2.5 \mathrm{~cm}^{2}$ and maximum 8.43 in population density of 127.39 insects per $2.5 \mathrm{~cm}^{2}$. The percent loss of lac insects during $155^{\text {th }}-185^{\text {th }}$ day was just 2.14 percent in population density of 127.39 insects per $2.5 \mathrm{~cm}^{2}$, while maximum loss of 5.16 percent was in population density of 50 insects per $2.5 \mathrm{~cm}^{2}$.

Adult male lac insects were observed in between $129^{\text {th }}-143^{\text {th }}$ day after BLI. The mean number of male lac insects maximum (6.67) with population density of 127.39 insects per $2.5 \mathrm{~cm}^{2}$, while minimum 1.39 in the population density of 60 insects per $2.5 \mathrm{~cm}^{2}$. The mean number of female lac insects maximum 27.55 with population density of 100 insects per $2.5 \mathrm{~cm}^{2}$ while minimum 10.87 in the 
population density of 127.39 insects per $2.5 \mathrm{~cm}^{2}$. The female to male ratio was highest $(27.55: 1)$ in the population density of 100 insects per $2.5 \mathrm{~cm}^{2}$ while the female to male ratio was lowest $(10.87: 1)$ in the population density of 127.39 insects per $2.5 \mathrm{~cm}^{2}$.

\section{Acknowledgment}

Authors are grateful to the Director Research Services, JNKVV, Jabalpur for all technical guidance and support, as well as Adarsh lac samiti, Jamankhari village, Tehsil Barghat, district Seoni for providing quality brood lac.

\section{References}

Anonymous. 2005. Annual climate summary 2005. Government of India, Ministry of Earth Sciences, India Meteorological Department, Pune, India. Pp. 1-25.

Basiago AD. 1999. Economic, social, and environmental sustainability in development theory and urban planning practice. The Environmentalist, 19: 145161.

Bhalerao, KR. 2013. Study on Predator surveillance and its management on Rangeeni lac in Barghat block district Seoni Madhya Pradesh. M.Sc. (Ag.) Thesis submitted JNKVV, Jabalpur.

Ghugal SG, Thomas M and Pachori R. 2015. Performance of Katki Lac on Nutrient Managed of Butea monosperma (Lam.) Taub. Trends in Biosciences 8(24), Print. Pp. 6873- 6877.

Ghugal SG, Thomas M. Upadhyay A and Sharma HL. 2016. Foliar Application of Nutrients and PGR on Butea monosperma and Survival of Kerria lacca Kerr. Advances in Life Sciences 5(1), Print. Pp. 159-163.

Grosholz ED. 1992 Interactions of Intraspecific, Interspecific, and Apparent Competition with Host-Pathogen Population Dynamics. Ecology 73 (2): 507-514

Gurjar R. 2016. Study on the Effect of Foliar Application of Nitrogen and PGR on
Butea monosperma on Katki Crop Production. M.Sc. Thesis. JNKVV, Jabalpur, M.P.

Hansen TF, Stenseth NC, Henttonen H, Tast J. 1999. Proceedings of the National Academy of Sciences Feb 1999, 96 (3) 986-991.

Hazarika LK, Das P, Saikia R and Islam AN. 2018. Settlement behavior of lac insect, Kerria lacca crawlers. Journal of Entomology and Zoology Studies; 6(6): 1267-1269

Janghel S. 2013. Study on comparative efficacy of insecticides in Katki crop for predator management on Rangeeni lac crop on Zizyphus mauritiana in Malara village, Seoni District. M.Sc. Thesis. JNKVV, Jabalpur, M.P.

Kalahal C, Swami H and Lekha. 2017. Productivity-linked parameters of the Rangeeni strain Lac Insect, Kerria lacca Kerr. on Pigeonpea, Cajanus cajan Linn. at Rajasthan. Journal of Entomology and Zoology Studies; 5(3): 1745-1751.

Khobragade D, Thomas M, Pachori R, Sharma JL and Shrivastava A. 2012. Farmer participatory trial on the predator management of Lac insect $K$. lawwi Kerr. in Anuppur District, Madhya Pradesh. Journal of Tropical Forestry, 28(1\&2): 38-45.

Khobragade D. 2010. Studies on the Incidence on major predators of Kerria lacca Kerr. and their management in Baishakhi lac crop in Anuppur district, Madhya Pradesh. M.Sc. (Ag.) Thesis submitted JNKVV, Jabalpur.

Kumar S, Thomas M, Lal N, Virendra and Markam VK. 2017. Effect of nutrition in Palas (Butea monosperma Lam.) on the survivability of lac insect. The Pharma Innovation Journal. 6(8): 320-324.

Mohanta J, Dey DG and Mohanty N. 2012. Performance of lac insect, Kerria lacca Kerr. in conventional and nonconventional cultivation around Similipal Biosphere Reserve, Odisha, India. Bioscan, 7: 237-240.

Mohanta J, Mohanty N and Dey DG. 2013. Life 
cycle of lac insect, Kerria lacca Kerr. in simipal biosphere reserve. Indian Journal of Entomology. 75: 26-30.

Namdev BK, Thomas M, Kurmi A, Thakur AS and Upadhyaya A. 2015. Impact of nutrient management of Zizyphus mauritiana (lamb.) On the yield of kusmi lac. The Bioscan. 10(3): 1219-1222.

Namdev BK. 2014. Study on the performance of Aghani crop of Kusmi lac on nutrient managed Zizyphus mauritiana under heavy rainfall condition. M. Sc. (Ag.) Thesis submitted JNKVV, Jabalpur.

Pal G. 2009. Impact of scientific lac cultivation training on lac economy: A study in Jharkhand. Agric. Econ. Res. Rev., 22: 139-143.

Patel B. 2013. Comparative performance of Kusmi and Rangeeni lac on Ber. M.Sc. Thesis. JNKVV, Jabalpur, M.P.

Ramani R, Baboo B and Goswami DN. 2007. Lac- An introduction. Indian Lac Research Institute, Ranchi 12.

Rathore V. 2011. Comparative performance of three local Rangeeni Lac cultivar on Zyziphus maurtiana in Dharna village, Seoni district, Madhya Pradesh. M.sc. (Ag) Thesis, submitted, JNKVV, Jabalpur.

Sahu S. 2016. Survival and Yield of Rangeeni Lac insect on Butea monosperma (Lam) treated with different Micronutrients and Humic acid. M.sc. (Ag) Thesis, submitted, JNKVV, Jabalpur.

Shah TH and Thomas M. 2018. Survival of kusmi lac insect (Kerria lacca Kerr.) on nutrient managed Zizyphus mauritiana. Indian Journal of Entomology, 80(1): 56-63.

Shah TH, Thomas M and Bhandari R. 2014. Impact of nutrient management in Zizyphus mauritiana (Lamb.) on the survivability of lac insect and the yield of Aghani crop of Kusmi lac. India Journal of Entomology and Zoology Studies; 2 (5): 160-163.

Shah TH, Thomas M and Bhandari R. 2015. Economic analysis of kusmi lac production on Zizyphus mauritiana (Lamb.) under different fertilizer treatments. Journal of Environmental and Agricultural Science (ISSN : 23138629); 4:37-41.

Shah TH, Thomas M and Bhandari R. 2015. Economic analysis of kusmi lac production on Zizyphus mauritiana (Lamb.) under different fertilizer treatments. Journal of Environmental and Agricultural Science (ISSN : 23138629); 4:37-41.

Sharma H, Ghugal SG, Thomas M and Pachori R. 2015. Impact of Nutrient Management in Butea Monosperma (Lam.) Taub. on the Survivability of Kerria Lacca (Kerr). Trends in Biosciences 8(23): 6682-6687.

Sharma S, Swami H, Lekha, Bhan C and Bairwa HL. 2018. Life cycle of lac insect on different hosts. Indian Journal of Applied Entomology 32(1): 19-23.

\section{How to cite this article:}

Shivam Vajpayee, Rahul Patidar, Sumit Kakade, Moni Thomas, Niraj Tripathi, A. K. Bhowmick, A. S. Gontia, P. S. Kulhare and Sharma, H. L. 2019. Effect of Population Density of Kerria lacca Kerr. on its Growth and Survival. Int.J.Curr.Microbiol.App.Sci. 8(12): 912-924. doi: https://doi.org/10.20546/ijcmas.2019.812.117 